\title{
XLVII. On the effect of pressure on thermometer- bulbs, and on some sources of error in thermometers
}

\section{Spencer Umfreville Pickering M.A.}

To cite this article: Spencer Umfreville Pickering M.A. (1887) XLVII. On the effect of pressure on thermometer-bulbs, and on some sources of error in thermometers, Philosophical Magazine Series 5, 23:144, 406-411, DOI: 10.1080/14786448708628029

To link to this article: http://dx.doi.org/10.1080/14786448708628029

冓 Published online: 29 Apr 2009.

Submit your article to this journal $[\pi$

Џll Article views: 2

Q View related articles $\sqsubset$ 
XLVII. On the Effect of Pressure on Thermometer-bulbs, and on some Sources of Error in Thermometers. By SPENCER Umareville Pickering, M.A., Professor of Chemistry at Bedford College*.

THE great difficulty which exists in obtaining exact con1 cordance between two thermometers throughout a considerable range of their scales must have been experienced by all who have had occasion to require such concordance. In the course of a series of experiments, in which the temperature-disturbance in a calorimeter was measured simultaneously with two instruments, I was much struck by the appearance of a certain amount of regularity in the difference in the results yielded by the two instruments, which, according to direct comparisons with each other through longer ranges of temperature, should have been absolutely concordant. The instruments being open in the scale and having large bulbs, I was led to seek for an explanation of these discrepancies in irregularities in the expansion of the bulbs under the pressure of the column of mercury in the tube.

The effect of pressure on a thermometer-bulb has been investigated by Egen (Pogg. Ann. xi. p. 283), and by Mills (Roy. Soc. Edin. xxix. p. 285), with the general result of showing that the expansion experienced is directly proportional to the pressure. But although the pressures employed in Mills's experiments were considerable (ranging up to 134 atmospheres), the thermometers which he examined were not of the most delicate character, and the coefficient of expansion was but small in comparison with that possessed by most calorimetric instruments. In the present experiments the bulb of the thermometer was enclosed in a small thin brass cylinder, which was connected with a pump, by means of which a vacuum, or pressure up to two atmospheres, might be produced. The case enclosing the bulb was previously filled with melting ice and placed in a large vessel of the same, the zero point of the thermometer having been previously adjusted so as to be slightly above the level of the ice.

Three instruments were investigated in this manner, Nos. 62839,63616 , and 65108 , of which the details of construction are given in the table ii. of the preceding communication (see also Phil. Mag. 1886, vol. xxi. pp. 331, 340). About twenty observations at different pressures were made in each case, and the results are given in Table I., where are entered the observed pressures and readings in millim., and also

* Communicated by the Physical Society : read April 23, 1887. 
Effect of Pressure on Thermometer-bulbs.

\begin{tabular}{|c|c|c|c|c|}
\hline 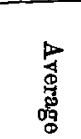 & 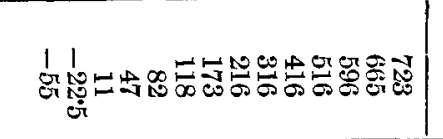 & 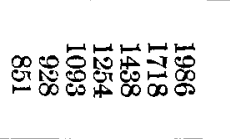 & 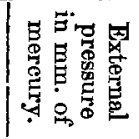 & \multirow{4}{*}{ 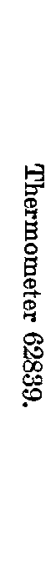 } \\
\hline \multirow{3}{*}{ 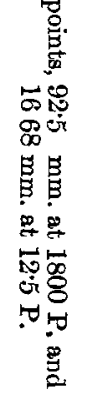 } & 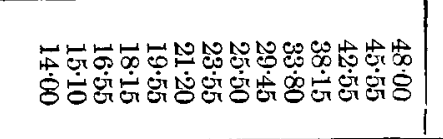 & 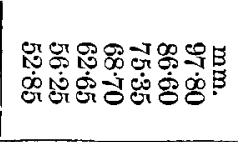 & 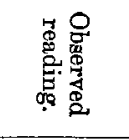 & \\
\hline & 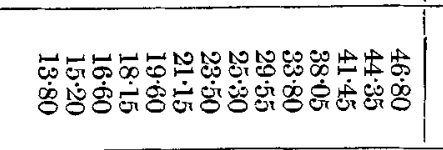 & 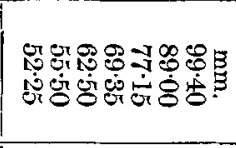 & 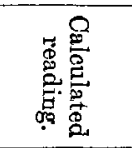 & \\
\hline & 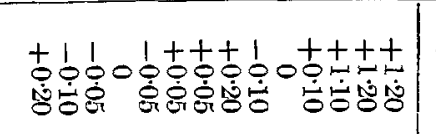 & 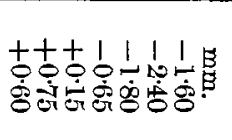 & 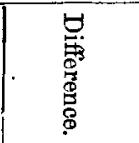 & \\
\hline \multirow{4}{*}{ 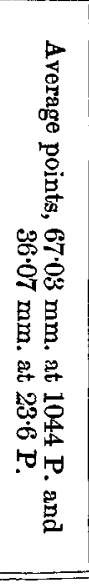 } & 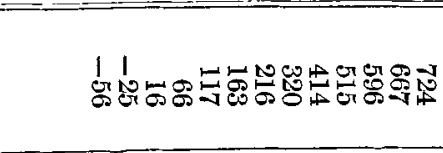 & 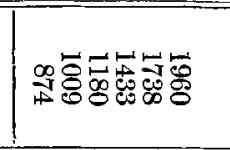 & 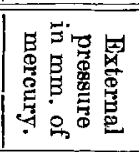 & \multirow{4}{*}{ 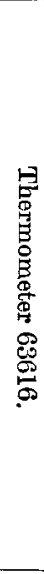 } \\
\hline & 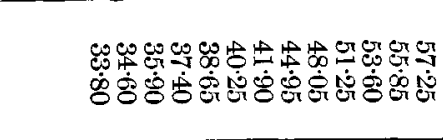 & 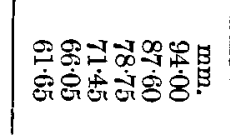 & 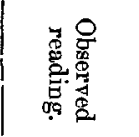 & \\
\hline & 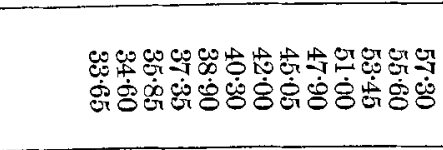 & 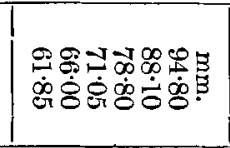 & 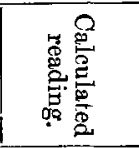 & \\
\hline & 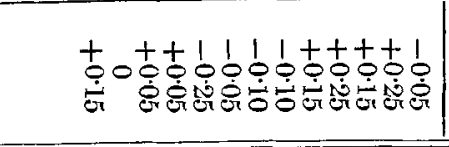 & 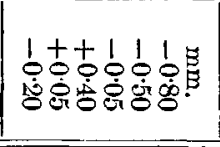 & 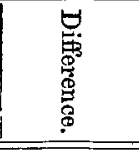 & \\
\hline \multirow{4}{*}{ 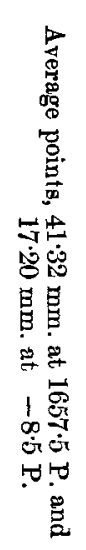 } & \multicolumn{2}{|c|}{ 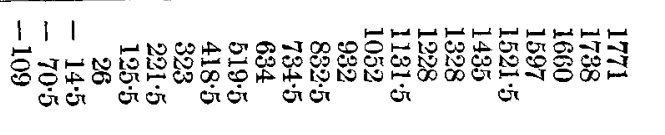 } & 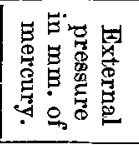 & \multirow{4}{*}{ 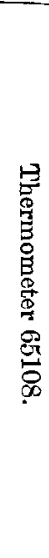 } \\
\hline & \multicolumn{2}{|c|}{ 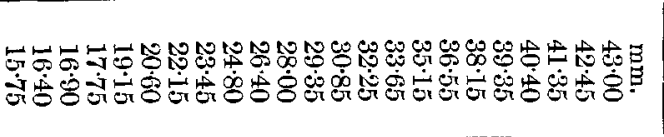 } & 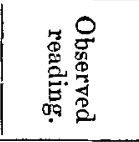 & \\
\hline & \multicolumn{2}{|c|}{ 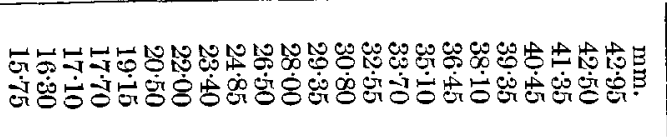 } & 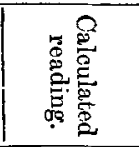 & \\
\hline & \multicolumn{2}{|c|}{ 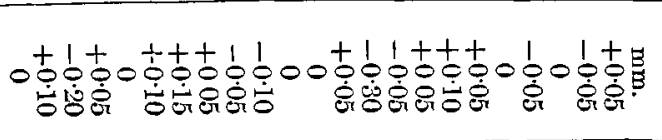 } & 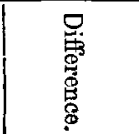 & \\
\hline
\end{tabular}


the readings, calculated on the assumption that the alteration in height of the column is directly proportional to the pressure; these calculated values being deduced from the average points given at the foot of the table. With the last-mentioned instrument (65108) the effect of pressure on the bulb would appear to cause a very regular expansion; there are only three observations which differ from the calculated values by more than 0.1 nillim., while the average difference amounts to about 0.05 millim. only. With the other two instruments the observations at the higher pressures cannot be much relied on, since the pressures were ascertained by means of a Bourdon's gauge, instead of a column of mercury as in the other cases; and this gauge was afterwards found to be untrustworthy. Omitting these observations, we find that, in case of No. 63616 , where the coefficient of apparent expansion of the bulb was twice as great as that of 65108 , the error in the readings is considerably larger, amounting to as much as 0.12 millim. on the average, while the grouping together of the positive and negative differences is well marked. It is only with No. 62839, however, which possessed a still greater coefficient of expansion, that the differences become so large as to render it quite impossible to attribute them to mere experimental error. As the pressure is increased above 500 millim., the bulb begins to contract far more than it should, causing a difference of as much as 1.2 millim. between the observed and calculated readings; it then contracts less, crosses the line representing the calculated values and for pressures from 1100 up to 1986 millim. (if these higher results may be trusted) does not contract as much as it should do*. The action of the bulb under pressure is evidently not regular.

As the differences in the calorimetric results above mentioned were observed with the thermometers '616 and '08, which behaved normally, or nearly so, under pressure, as well as with other instruments with bulbs of considerably smaller expansibility, it is impossible to attribute these differences to the cause suggested; at the same time, however, the present investigation leads to results of considerable practical importance. It is evident that where the coefficient of expansion of the bulb is large, as with ' 39 , irregularities in expansion sufficient to introduce considerable errors may occur; the bulb, when subjected to pressure, would appear to behave

* Care was of course taken that the thermometer should not be read till the column had attained a position of equilibrium. The top of the instrument was tapped throughout the experiments by means of the tapping apparatus, and the column read at intervals of one minute till it was found to be perfectly stationary. 
in a manner analogous to that often noticed with thin tin plate vessels, where a small addition or removal of pressure will cause a sudden and considerable alteration in the form of the vessel. It would certainly be advisable, in the case of any thermometer required for very delicate work, to examine it under pressure to ascertain whether its action be uniform or not. In order to reduce the chances of irregular action, it is necessary to render the bulb as inexpansible as possible. From the fact that the thermometer 63616 showed a slight amount of irregularity in its action, we may place the limits of expansibility desirable in a very fine instrument at a number between that of this instrument and that of 65108 ; the coefficient of expansion should not exceed $0 \cdot 000,000,03$, or the apparent expansion 0.02 millim. of the mercurial column per millim. of pressure.

An examination of table ii. of the preceding communication will show at once the increase of rigidity obtained by having the bulb made out of a glass cylinder instead of being blown before the lamp ; the instruments ' 83 and ' $39 \mathrm{~B}$ are the only ones mentioned in this table which had blown bulbs, and the coefficients of expansion in their cases are higher than in any other case, although their bulbs were only $\frac{1}{2}$ and $\frac{1}{3}$ as big as those of most of the other instruments. Again, the thermometers ' 83 and ' 16 were identical in all respects except as regards their bulbs, and here the blown bulb ('83) possesses only half the strength of that made out of cylinder.

Although it seems probable, prima facie, that a blown bulb, however well constructed, would not be so uniform as a cylinder bulb, these facts of course do not prove that such is necessarily the case, as the thickness of the walls of the bulbs was not known; but it does prove that, by ordering a thermometer with a cylinder bulb, we should in all probability get an instrument possessing nearly twice the strength of one with a blown bulb. A further very considerable addition of strength may be gained by having the bulb made double instead of single. The instruments Nos. '616, '08, and '61 possessed double bulbs made out of glass cylinder; and a comparison of them with ' $83 \mathrm{~B}$ and ' 39 , which had single bulbs made out of cylinder also, will show the advantages of the double bulb. For thermometers to be used in a liquid which is stirred in a thoroughly efficient manner, the thickness of the walls of the tube forming the bulb may be very considerable. The instruments Nos.' 08 and ' 61 , which contain between 40 and 50 grams of mercury, will take the temperature of the liquid in the calorimeter in about 5 seconds, although their bulbs are 0.75 millim. thick in the walls. 
Although the effect of different pressures on the bulb did not appear to produce irregularities such as would account for all the difficulties experienced in getting two instruments to correspond perfectly throughout their scales, it was thought possible that the expansibility of the bulbs under pressure might be influenced to a considerable extent by the temperature of the experiment, and that this might produce discordance between two instruments which had been compared with the same standard but at different temperatures. To investigate this, the behaviour of No. '08 under pressure was examined at $12^{\circ} \mathrm{C}$. As it was impossible to keep the temperature of the bath absolutely constant throughout the series of experiments, the reading at any pressure $P_{1}$ was compared with that at $\mathrm{P}$ by taking the mean of two observations at $\mathrm{P}$, made immediately before and immediately after the observation at $P_{1}$. In the following Table the value of the constant

Thermometer '08. Under pressure at $12^{\circ}$.

\begin{tabular}{|c|c|}
\hline $\mathbf{P}_{\mathbf{L}}-\mathbf{P .}$ & $\frac{\mathbf{R}_{1}-\mathbf{R}}{\mathrm{P}_{\mathbf{1}}-\mathbf{P}}$ \\
\hline millim. & \\
-500 & 0.01445 \\
-400 & 0.01445 \\
-300 & 0.01434 \\
-200 & 0.01380 \\
+200 & 0.01470 \\
+300 & 0.01469 \\
$+\ldots 00$ & 0.01438 \\
+500 & 0.01462 \\
+600 & 0.01447 \\
& 0.01455 \\
Mean .............. & 0.01457 \\
\hline
\end{tabular}

obtained from $\frac{R_{1}-R}{P_{1}-\bar{P}}\left(R_{1}\right.$ and $R$ being the readings at $P_{1}$ and $P$ respectively) is given in the second column, while $P_{1}-P$ is given in the first column. $P$ was in all cases the atmospheric pressure. The mean value of the constant (the coefficient of apparent expansion) is 0.0145 , a number absolutely identical with that found at $0^{\circ}$ (table ii., preceding paper), which shows that small alterations of temperature, such as would occur in standardizing delicate calorimetric thermometers, produce no appreciable alteration in the rigidity of the bulbs. The causes producing non-concordance of ther- 
mometers under certain circumstances still remains to be discovered*.

I may mention one source of error in thermometric work which attains considerable dimensions when dealing with tubes of very fine bore. These tubes, even when of the most perfect description obtainable, generally possess a few points at which the mercury column experiences a difficulty in passing: the mercury, when it has reached such a point, sticks there an appreciable time, and then passes it suddenly with a jerk; sometimes, even, the mercury sticks so persistently that the column will separate sooner than pass it. These points do not indicate any contraction which is sufficient to affect the results of calibration, and are probably due to some difference in the nature of the glass, for they may be developed by heating the thermometer-tube externally with a very small flame up to about $400^{\circ}$. The error of taking a reading while the mercury is sticking at such a point may, I estimate, amount sometimes to as much as $0.5 \mathrm{millim}$. All delicate thermometers should be carefully examined in order to ascertain the position of such points, and they should be avoided, if possible, in any work with the instrument.

In any thermochemical work in which the effect of temperature on a given reaction is being studied, many of the sources of error inherent in the use of thermometers may be avoided by using the same portion of the stem of the instrument, whatever the actual temperature may be. To effect this, the zero-point is altered in each experiment by removing some of the mercury into the upper chamber of the thermomoter. Formerly I removed the requisite nmount of mercury by the application of a very small flame to a point just below this chamber; but I now adopt a method which is much safer, more expeditious, and equally exact. A fine tube, somewhat wider than the stem of the thermometer, is affixed to the upper end of the stem, and in this tube there is a small contraction or "knife-edge," sufficiently wide to permit of the mercury passing it either upwards or downwards, but yet so narrow that a slight swing of the instrument will cause the column of mercury to break off at it, that portion of the mercury which is above the knife-edge passing up into the upper chamber. By this means any point on the stem may be adjusted with ease to within $0^{\circ} 02$ of any given temperature.

* For an unexplained instance of non-accordance of results obtained with different thermometers, and also with different portions of the stem of the same thermometer, see Chem. Soc. Trans. 1887, pp. 304, 322. 